\title{
Exploring new ways of integration, visualization and interaction with Geotechnical and Geophysical Data
}

\author{
Vítor Gonçalves \\ Polytechnic Institute of Castelo Branco \\ PhD student in IEETA (Univ. Aveiro) \\ Castelo Branco, Portugal \\ vitor@esart.ipcb.pt
}

\section{Paulo Dias}

IEETA / Department of Electronics Telecommunication and Informatics

Univ. Aveiro

Aveiro, Portugal

paulo.dias@ua.pt
Fernando Almeida

Geosciences Department

Univ. Aveiro

Aveiro, Portugal

fernandoalmeida@ua.pt

\section{Beatriz Sousa Santos}

IEETA / Department of Electronics Telecommunication and Informatics

Univ. Aveiro

Aveiro, Portugal bss@ua.pt

\begin{abstract}
The work presented in this paper aims at exploring new ways of integrating, visualizing and interacting with geotechnical and geophysical data that may be more rich and interactive than those offered by most current Geographic Information Systems (GIS). Some visualization techniques enabling simultaneous visualization of the several data types available in our case study are proposed. Moreover, methods were developed to guide experts while defining layers and other relevant geological structures. The work is still in an early stage and is main goal has been assessing the validity and adequacy of the proposed techniques to the specific geotechnical and geophysical data under consideration.
\end{abstract}

Keywords-component; Visualization; geotechnical and geophysical data; VTK (Visualization Toolkit)

Full article at link:

http://ieeexplore.ieee.org/xpls/abs_all.jsp?arnumber=55713 